\title{
Asymmetric Allylic Substitution in Water with a Polymeric Pd Catalyst
}<smiles>CC(=O)OC1C=CC(OC(C)=O)C1</smiles>

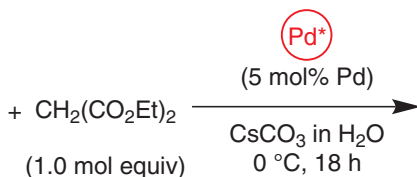

(Pd)<smiles>CC(=O)OC1C=CC(OC(C)=O)C1</smiles>

1

$+\mathrm{NH}\left(\mathrm{CH}_{2} \mathrm{Ph}\right)_{2}$

(1.0 mol equiv)

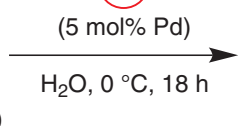

Pd<smiles>CC(=O)OC1C=CC(OC(C)=O)C1</smiles>

$\mathrm{ArOH}$

(1.0 mol equiv)
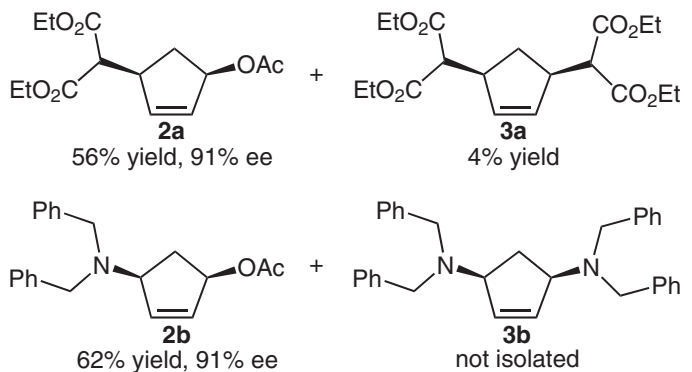

not isolated

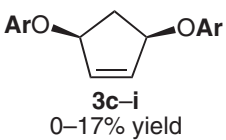

$\mathrm{Ar}=\mathrm{Ph}, 2-\mathrm{BnOC}_{6} \mathrm{H}_{4}, 2-\mathrm{ClC}_{6} \mathrm{H}_{4}, 2-\mathrm{BrC}_{6} \mathrm{H}_{4}, 2,6-\mathrm{diMeC}_{6} \mathrm{H}_{3}, 3-\mathrm{MeOC}_{6} \mathrm{H}_{4}, 4-t-\mathrm{BuC}_{6} \mathrm{H}_{4}$
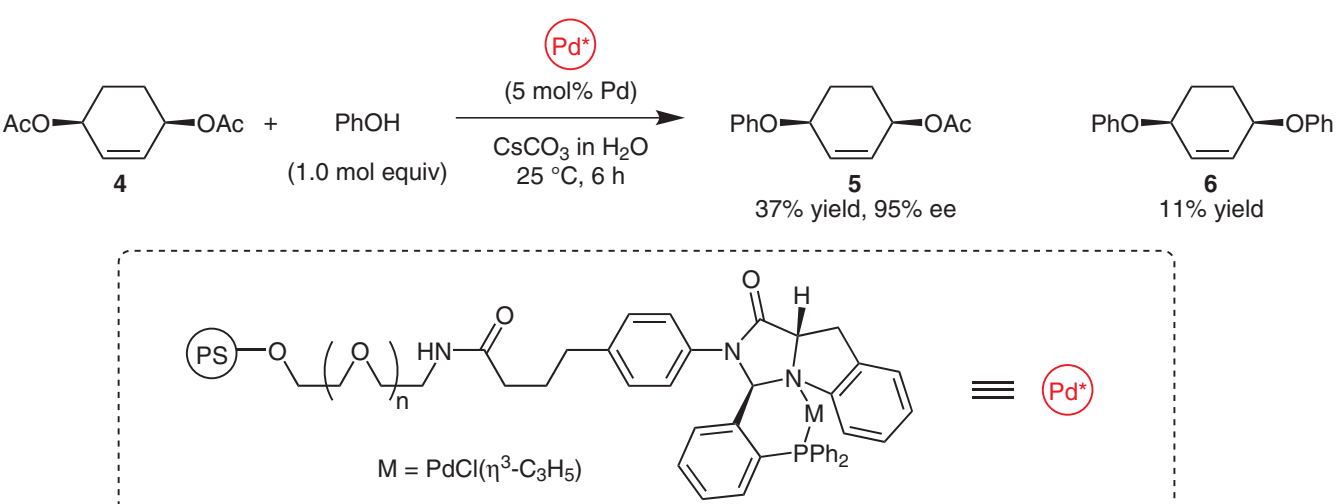

$\equiv\left(\mathrm{Pd}^{*}\right.$

Significance: Asymmetric $\pi$-allylic substitution of meso-1,4-diacetoxycycloalkenes was performed with an amphiphilic PS-PEG resin-supported chiral phosphine-palladium complex. Thus, the reaction of cis-1,4-diacetoxycyclopentene (meso-1) with diethyl malonate, dibenzylamine and phenols in water gave the corresponding 1-acetoxy-4substituted cyclopentenes 2a-i with 90-99\% ee in 43-64\% yield. Cyclohexenyl ester (meso-4) also underwent etherification with phenol to give $\mathbf{5}$ in $37 \%$ yield (95\% ee) and $11 \%$ of 6 .
Comment: The authors have reported earlier the preparation and utility of the polymeric chiral phosphine-palladium complex used here (J. Am. Chem. Soc. 2001, 123, 2919; Org. Lett. 2004, 6, 281; Org. Lett. 2005, 7, 291; Tetrahedron: Asymmetry 2006, 17, 161; J. Org. Chem. 2006, 71 , 8644). The reaction pathway giving high enantiomeric excess of the monosubstituted products includes kinetic resolution steps forming disubstituted 3.

sYNFacts Contributors: Yasuhiro Uozumi, Yoichi M. A. Yamada, Toshihiro Watanabe 